\title{
Regenerative food systems and the conservation of change
}

\author{
Philip A. Loring ${ }^{1}$ (D) \\ Accepted: 1 November 2021 / Published online: 9 November 2021 \\ (c) The Author(s), under exclusive licence to Springer Nature B.V. 2021
}

\begin{abstract}
In recent years, interest has increased in regenerative practices as a strategy for transforming food systems and solving major environmental problems such as biodiversity loss and climate change. However, debates persist regarding these practices and how they ought to be defined. This paper presents a framework for exploring the regenerative potential of food systems, focusing on how food systems activities and technologies are organized rather than the specific technologies or practices being employed. The paper begins with a brief review of debates over sustainable food systems and the varying ways that regenerative food systems have been defined and theorized. Then, it provides the theoretical backing of the framework-the conservation of change principle - which is an interpretation of the laws of thermodynamics and theories of adaptive change as relevant to the regenerative capacity of living systems. Next, the paper introduces the framework itself, which comprises two independent but intersecting dimensions of food systems organization: resource diversity and livelihood flexibility. These two dimensions result in four archetypical regimes for food systems: degenerative, regenerative, impoverished, and coerced. The paper defines each and offers real-world examples. Finally, the paper concludes with a discussion of pathways for transforming food systems and opportunities for additional research.
\end{abstract}

Keywords Agroecology · Entropy · Food system transformation · Regenerative agriculture · Socio-technical regimes · Sustainable agriculture $\cdot$ Social-ecological traps

\section{Introduction}

There is a pressing need to rapidly redesign global food systems around practices that can meet ambitious goals for ecological sustainability and social justice (Rockström et al. 2020). Global food systems have succeeded in consistently increasing food production, both in sum and per capita, since the 1960s, while also keeping food prices relatively stable (Loring and Sanyal 2021). However, despite producing ample quantities of food, these food systems fail to ensure food security for a billion or more people worldwide (Holt-Giménez et al. 2012). Too, the continued growth of these systems has only been possible because of myriad unsustainable and unjust practices that degrade ecosystems (Campbell et al. 2017), destabilize global climate (Vermeulen et al. 2012), and impoverish rural communities (Sen

Philip A. Loring

phil.loring@uoguelph.ca

1 Department of Geography, Environment, and Geomatics, Arrell Food Institute, University of Guelph, 50 Stone Road E., Guelph, ON N1G2W1, Canada
1983; Hornborg 2009). Indeed, numerous segments of the global food system are arguably only economically feasible so long as they can be subsidized by cheap chemical inputs and labor (Rist et al. 2014). Some scholars have gone so far as to describe today's industrially oriented systems as "coerced", or "zombie regimes", because they lack internal resilience and are only sustainable as long as their hunger for these subsidies can be fed (Rist et al. 2014; Angeler et al. 2020).

Attempts to build alternative food systems that address environmental issues like climate change while also doing a better job of providing people with sufficient, safe, and culturally appropriate food are well underway in a variety of locales (Trivette 2012; Witter and Stoll 2017; IPES-Food 2020). Local and Indigenous food movements, regenerative grazing, cellular agriculture, and digital agriculture are some of the noteworthy ways that people are pursuing innovation and reform, though the specific aims, scope, and merits of these strategies are heavily contested (Fraser et al. 2016; Rotz et al. 2019). At a minimum, the prevalence of diverse discourses and technological imaginaries regarding the future of food indicates a widespread societal engagement with, if not consensus 
regarding, the basic premise that our food systems urgently need to be transformed.

One critique that is raised repeatedly in debates and discussions about food system reform relates to the matters of definitions and standardization. The introduction of each new concept to the food systems discourse-sustainable, local, resilient, and now, regenerative- - has come with a concomitant flurry of debate and discussion about how to best define, categorize, certify, or regulate these concepts. Some argue that these concepts are too vague or impossible to define (Born and Purcell 2006), while others encourage rigorous definition and the creation of standards to make these concepts meaningful and marketable (Sutton 1996; Newton et al. 2020). Others still argue that these concepts are necessarily emergent in nature, and only take shape as people take them up and put them into practice in ways that work for their local social and ecological contexts (Eriksen 2013; Witter and Stoll 2017; Penca 2019).

From the perspective of paradigm change, part of what makes concepts like sustainable, local, and regenerative potentially revolutionary is their plurality, because food systems issues and solutions are inherently place-based (Katz-Rosene 2020; Loring 2020a). Nevertheless, these concepts must convey meaningful information if they are to inspire much needed changes in food production and confidence in consumers. Likewise, a focus on the first principles that drive various food systems configurations can help us to identify the root causes of problems with the current paradigm, so we can develop the strategies that might collectively come to constitute the new paradigm (or paradigms) that replace it.

In this paper I present a framework rooted in human ecology for making sense of the various possible configurations of food production systems, one that maintains space for pluralism while still highlighting meaningful differences in how those configurations relate to social and ecological outcomes. Rather than focusing on specific food production practices or technologies, the framework focuses on how food systems are organized: specifically, on patterns of livelihood strategies and resource diversity. First, I provide some background on debates over sustainable food systems and the emergence of regenerative agriculture. I follow this with a discussion of the framework, its theoretical underpinnings in ecology and thermodynamics, and the four archetypical regimes for food systems that the framework establishes: regenerative, degenerative, coerced, and impoverished. I then conclude with a discussion of pathways for transforming food systems and opportunities for additional research.

\section{Background}

Much discussion has been had in the last few decades over the appropriate scales, systems, and technologies for redesigning global food systems and attending to food security challenges (Kloppenburg et al. 1996; Born and Purcell 2006; Eriksen 2013; Fraser et al. 2016). Numerous strategies and solutions are being explored and promoted, including food systems localization (Kloppenburg et al. 1996; Trivette 2012), organic production (Reganold and Wachter 2016), sustainable intensification (Garnett et al. 2013), agroecology (Pereira et al. 2018), digital agriculture (Fraser and Campbell 2019), and regenerative agriculture (Newton et al. 2020; Schreefel et al. 2020). These various positionalities have spawned persistent and often heated debates that, while important, are arguably hindering progress on achieving the rapid transformations we need to avoid further climate and food systems breakdown (Fraser et al. 2016; Rockström et al. 2020).

One challenge in these debates is that the arguments are not necessarily being made on the same terms: some emphasize matters of technology or scale, such as inputs, outputs, and food miles, while others focus on social and organizational matters such as equity, sovereignty, and social-ecological linkages and feedbacks. While the former are no doubt critical considerations when thinking about how to improve food production, the social and ecological outcomes of the various technologies we have at our disposal are necessarily mediated by the cultural and ecological characteristics of where and how these technologies are implemented (Kottak 1990; Vandermeer et al. 2018). Sustainable livestock management, for example, will take dramatically different forms depending on the details of the landscape, systems of land tenure, and the cultures practicing it (Savory 1988; Dunford 2002; Saunders and Barber 2008). It is thus inadvisable to hastily proclaim that any specific set of foods, food production technologies, or scales of operation are universally sustainable or not (Born and Purcell 2006; Katz-Rosene 2020).

Consider regenerative agriculture- a collection of integrated practices for food production that emphasize soil health, carbon sequestration, ecosystem resilience, and nutrient-dense foods (Ikerd 2021). At the heart of regenerative agriculture is a commitment to improving the ecological (and sometimes social) outcomes of agricultural practices, usually starting with soil health as a foundation for addressing issues related to climate change, water quality, land productivity, and biodiversity conservation (Francis et al. 1986; Toensmeier 2016; Rhodes 2017; Schreefel et al. 2020). Research suggests that regenerative practices can achieve win-win scenarios: increasing on-farm profits while also improving other ecosystem services as well (LaCanne and Lundgren 2018). While not a new concept, regenerative agriculture has seen a major uptake in recent years by practitioners and corporate strategists in response to increased public awareness of the environmental impacts of agriculture. Definitions of regenerative agriculture vary widely (Newton et al. 2020; Schreefel et al. 2020), with some attending primarily to matters of process (e.g., reliance 
on organic methods or reduced tillage), while others emphasize critical outcomes (e.g., biodiversity, carbon sequestration) (Newton et al. 2020). Carbon in particular is often emphasized; carbon farming and carbon ranching have both become popular monikers for regenerative practices (White 2014; Toensmeier 2016). However, the scramble by agribusiness to adopt a regenerative identity has been plagued by inconsistencies, a lack of attention to context, and a less than critical approach to what various purportedly regenerative technologies can achieve (Giller et al. 2021).

Ikerd (2021) argues that the regenerative paradigm is not necessarily about soil, carbon, or specific technologies, but about energy and whether our cultural systems for food production work with, rather than against, the capacity of living systems to return energy from less useful to more useful forms. His argument rests on the principles of thermodynamics, specifically the second law, which establishes the tendency of energy to move from more useful to less useful forms. When we use energy entropy increases, which in practical terms means that the energy becomes less useful. But, living systems are adapted to work against the general trend of increasing entropy (England 2013), and are capable of reconfiguring used energy back into more usable forms. They do this through an intersecting, co-evolved tapestry of cycles of release and renewal that occur at multiple spatial and temporal scales (Gunderson and Holling 2002; Loring $2020 b$ ). From the fast cycles of soil microbes to decadal oscillations of predators and prey and the centennial cycles of forest succession, energy in living systems is repeatedly used and recovered, moving up, down, and across food webs, from low entropy to high entropy and back again, in an ongoing process of adaptive change.

What the second law of thermodynamics means for food systems is that this tapestry of change must always be conserved, lest their regenerative capacity be progressively eroded (Loring 2020b). To put it another way, wherever human activities actively resist natural variability and change to achieve highly structured and uniform outcomes, environmental degradation will result. Industrial monocultures, for example, simplify soils and agroecosystems with pesticides, herbicides, predator control, and the use of fertilizers. These technologies come with a high entropic cost because they disrupt the fast and slow cycles of changesuch as decomposition and nutrient cycling, plant and animal population dynamics, and landscape-level disturbance and succession - that would normally return used energy back to usable forms. By comparison, human activities that are organized to work with variability and change, via strategies that emphasize flexibility, steward cycles at multiple scales, and are responsive to environmental feedbacks, have high negentropic potential, meaning that they can contribute to or even enhance the regenerative capacity of natural systems (Travis et al. 2013; Ikerd 2021).
Collectively, I refer to this thermodynamic understanding of living systems as the 'conservation of change': a double entedre that refers both to the principle itself and to the practice of adhering to it, i.e., 'conserving change'. In a practical sense, wherever we manage our food systems for stability and uniformity, the more we risk diminishing the capacity of these systems to return energy from less useful to more useful forms. The principle tells us that change must happen somewhere; conserving that change means ensuring that our interactions with living systems work with rather than against the system of intersecting cycles that make regeneration possible. This can be as straightforward as adapting our diets to the seasonal availability of cultivated and wild foods or as extensive as adapting our food systems to complement multidecadal cycles of ecosystem disturbance and succession. As I discuss below, shifting cultivation, holistic ranching, Indigenous fire management, and to a lesser extent crop rotation and preserving food for out-of-season consumption are all examples of cultural practices that seek to embody the conservation of change principle.

\section{The framework}

Here, I present a framework for applying the conservation of change principle to food systems. My goal is not to impose prescriptive definitions for which practices or technologies count as regenerative or sustainable. Neither is it to establish a false binary that casts food systems as either regenerative or not. Rather, the goal of this framework is to make sense of the range of possible food system configurations and how these configurations relate to social and environmental outcomes. As noted, whether food systems achieve regenerative outcomes in the thermodynamic sense relates not merely to the technologies at play but also to the organization of the cultural systems implementing them.

The framework is based on the two key organizational properties introduced above: diversity and flexibility. Diversity is a central feature of ecosystem organization, one that is essential to both ecosystem health and productivity (Pimm 1984; Rapport et al. 1998; Hooper et al. 2005). While caveats exist (Chase and Leibold 2002; Hooper et al. 2005), there is generally a positive relationship between an ecosystem's diversity and its productivity, resilience, and stability (Pimm 1984; Fjeldsaå and Lovett 1997; Tilman et al. 2001). As such, food systems based on uniform ecologies tend to be less productive and prone to boom-and-bust dynamics (Clough et al. 2009; Barbier 2020). They can be successful for a time, but they leave people vulnerable to shocks or incentivized to act unsustainably (Fraser et al. 2005; R. S Steneck et al. 2011; Nayak et al. 2014; Henry and Johnson 2015). Food systems based on diverse ecologies, by comparison, provide people with multiple options for maintaining 
resilient livelihoods and nutrient-rich diets (Mulumba et al. 2012; Bogaard et al. 2017; Renard and Tilman 2019; Bernhardt and O'Connor 2021).

The second concept in the framework is flexibility, which refers to the extent to which our cultural systems can anticipate and respond to change. Flexibility is an adaptive strategy that is ubiquitous across the history of human societies (Thornton and Manasfi 2010). Whereas rigid food systems are tightly oriented to one or a few key livelihood strategies, flexible food systems exist when people have both the freedom and willingness to adapt their subsistence strategies when necessary (Loring and Gerlach 2010; Carlisle 2014). Flexibility confers resilience (Fraser et al. 2005; Carpenter and Brock 2008) but is only possible if people have sufficient opportunity to develop the ecological knowledge and social institutions they need to recognize and respond to environmental feedbacks that signal when change is necessary (Cinner et al. 2018).

Some have used the concept of portfolios to theorize the beneficial intersection of food system diversity and flexibility in practice (Fraser et al. 2005). Drawing on economic theory, Fraser and colleagues show that when people have access to multiple viable resources (diversity) and are willing and able to switch among them as necessary (flexibility), the resulting portfolio reduces vulnerability to future shocks. This portfolio effect has been observed in a variety of foodrelated settings, from subsistence food systems to global fisheries (Loring and Gerlach 2010; Beaudreau et al. 2019).

Here, I theorize diversity and flexibility as independent but intersecting dimensions that are central to food systems' regenerative potential (Fig. 1). Considered together, these two dimensions create four archetypical regimes - degenerative, regenerative, impoverished, and coerced-that we can use to characterize food systems and their likely entropic or negentropic outcomes at a variety of scales. Below, I discuss each of the four regimes, drawing on real world examples as possible. I present these in no particular order, starting with the upper left quadrant and proceeding clockwise, which I clarify here to avoid any implication that there is some natural progression or order to these regimes. Likewise, I do not present these as hard-fast categories, meaning that food systems in practice may well entail an assemblage of activities that exemplify different regimes to varying degrees.

\section{Regime 1: degenerative}

This regime involves food systems with access to high resource diversity, but rigid livelihood strategies that focus only on one or a few of the options that are available (Fig. 2a). The singular focus in degenerative regimes can be driven by strong economic incentives or subsidies, policies, or cultural norms. High value and demand for the resource incentivizes aggressive harvest, and there may

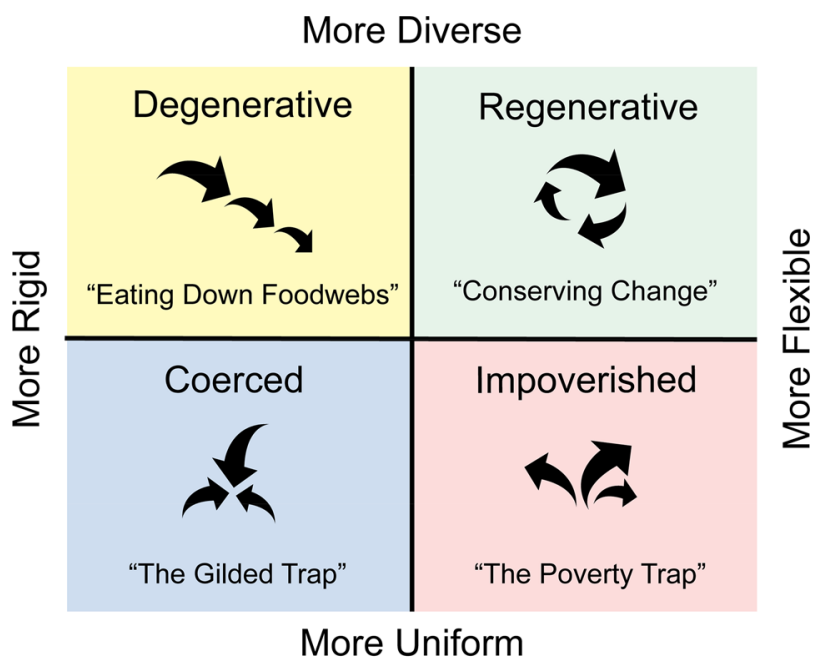

Fig. 1 A four-quadrant typology of food systems based on the flexibility of livelihoods ( $\mathrm{X}$ axis) and the diversity of resources available (Y axis). Degenerative regimes focus too rigidly on one or a few resources despite a diversity of options, which causes serial depletion of resources (e.g., fishing down the food web). Regenerative systems conserve change via flexible and diverse livelihood strategies. Livelihoods in impoverished systems are tightly coupled to, but trapped by, the limited resources available in a degraded environment. Coerced systems subsidize and favor a high-value ("gilded") resource at the expense of the surrounding ecosystem

be an assumption that the resources in question cannot be overharvested, or that they are so easily substituted that overharvest is irrelevant. Either way, even as evidence of environmental degradation emerges, people in these systems are unwilling or unable to switch to alternatives. Only when the targeted resources are extremely imperilled or collapsed do people finally move to other locales or more abundant resources.

"Fishing down the food web" is a well-described example of a degenerative regime (Pauly et al. 1998). In brief, this is a pattern of serial fisheries depletion, where fishers focus only on a few commercially valuable species, often starting with the largest and longest-lived predators, and then move on to progressively smaller and shorter-lived species as the larger ones become overfished. A similar pattern, fishing through the food web, happens when concurrent demand for smaller species increases, not because the larger ones are extirpated but because overall demand has grown beyond what the larger species can accommodate (Essington et al. 2006). Cultural preference remains for the largest species, with lower trophic level species generally going to those with lower incomes or for use as bait or feed in large species aquaculture (Stergiou et al. 2009).

Intensive livestock grazing and shifting cultivation are both examples of practices that have been implicated in degenerative regimes. Persistent overgrazing, for example, drives desertification, which forces ranchers to 


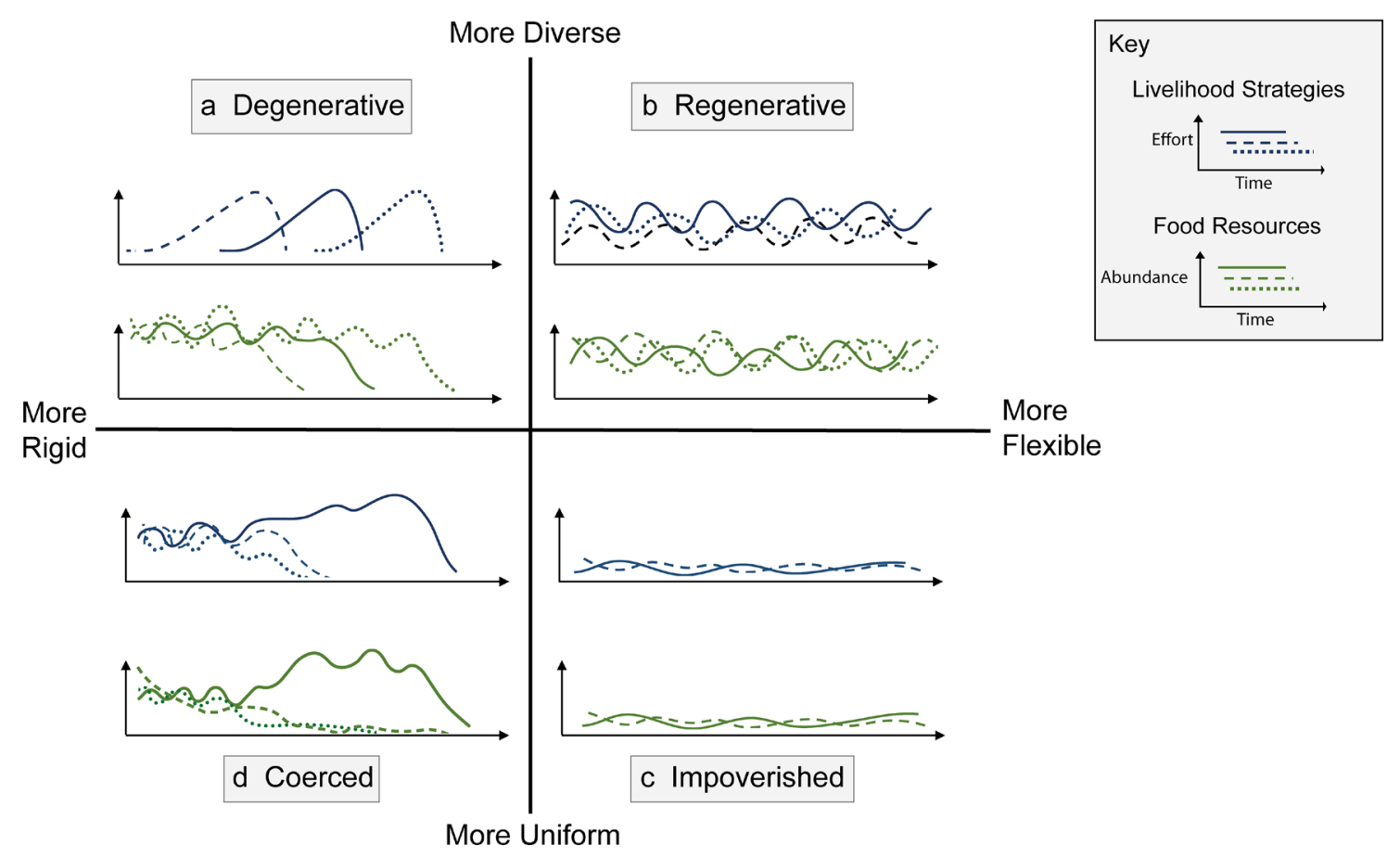

Fig. 2 Detail on patterns in livelihoods and resources for each of the four regimes. Charts in each of the four quadrants illustrate variability of specific livelihood strategies ( $\mathrm{Y}$ axes on upper charts) targeting specific resources ( $\mathrm{Y}$ axes on lower chart) over time (upper and lower $\mathrm{X}$ axes). Degenerative systems (a) deplete resources in a serial or simultaneous way, with livelihoods focusing on a single resource, ignoring environmental feedbacks, and only switching to an alternative when the targeted resources are fully depleted. Regenerative systems (b) entail a portfolio of flexible livelihood strategies that allow people to respond rapidly to changes in resource availability in the

abandon existing lands and move their animals to new lands, which are often acquired via new deforestation (Weber and Horst 2011). Likewise, intensive shifting cultivation, a practice where forests are cut and burned to create highly productive agricultural lands, can lead to a similar pattern of land abandonment and deforestation if farmers focus only on single crops after they burn or if they do not allow sufficient time between burns for fallow and regrowth (Brady 1996). As noted below, however, both of these technologies can also figure into regenerative systems when managed in a way that conserves change.

The degraded ecosystems that result from degenerative regimes can be highly resilient and unlikely to recover without direct intervention. Where these degenerative systems are perpetuated by outside actors, local people are then left coping with impoverished regimes, because they have no choice but to continue subsisting with what little is possible in this degraded environment (see Regime 3 , below). service of integrating human activities with endemic cycles of variability and change. Impoverished systems (c) are highly degraded and characterized by tight couplings between resource status and livelihoods, because people no choice but to harvest whatever resources are available, which prevents any regeneration. Coerced systems (d) often start from a position of livelihood and ecological diversity, but incentives arise to actively favor and cultivate highly valued resources at the expense of others. In so doing, regenerative capacity is depleted to the point where subsidies are required, and communities and ecosystems are vulnerable

\section{Regime 2: regenerative}

Regenerative systems are high in both flexibility and diversity and entail cultural systems that conserve change by emphasizing responsiveness to environmental cycles and feedbacks while also valuing ecosystem and food system diversity as outcomes (Fig. 2b). As noted, regenerative systems are high in negentropy because livelihood strategies work actively to complement or enhance natural cycles of release and renewal. As such, regenerative systems involve high levels of ecological expertise and strong norms and institutions that emphasize close relationships, active observation, and resource conservation (Berkes 2008).

There are numerous historical and contemporary examples of regenerative food systems, from ancient agriculture and mariculture to contemporary grazing (Dunford 2002; Bogaard et al. 2017; Loring 2020b). There is likewise extensive evidence that most pre-colonial Indigenous environmental practices were, and continue to be, regenerative in nature (Fisher et al. 2019; Ellis et al. 2021). Among these systems 
is shifting cultivation, including the ancient forest gardens of the Maya (Kleinman et al. 1995; Padoch and Pinedo-Vasquez 2010; Ford and Nigh 2015). As noted, shifting cultivation involves strategic, rotational burning and a mix of crop and orchard-like cultivation strategies that are adapted to work with the forests' multiple post-fire successional stages. While some modern examples of shifting cultivation cause degradation and have become vilified in modern environmental discourse (Brady 1996), there is extensive evidence that the numerous variations of the system practiced around the world were highly sustainable until disrupted by colonial invasion (Kleinman et al. 1995; Padoch and Pinedo-Vasquez 2010). To this day, the generative benefits of shifting cultivation are evident in the Amazon, in such forms as Amazonian dark earths (terra preta) and the widespread patterns of high biological and biocultural diversity that still characterize the region (Oliveira et al. 2020).

Cattle winterage, a recently revitalized practice in the Burren region of Ireland, is another example of a regenerative system (Dunford 2002; O'Rourke 2005). This is a unique and traditional form of transhumance where cattle are moved up to higher grazing areas in the winter, a time when the disturbances they cause by grazing and trampling, and the nutrient inputs they provide via their manure and urine, are all beneficial to the soil and plant community. The recovery of this system has driven major improvements in local biodiversity and water quality in the Burren and has also fueled a revitalization of traditional heritage in the region.

\section{Regime 3: impoverished}

Impoverished systems have limited diversity, but livelihoods remain flexible, in part because people must rely on whatever options are available for meeting their needs (Fig. 2c). As noted above, degenerative systems often leave impoverished systems in their wake, because local people are left with little choice but to cope with the social and ecological legacies of resource extraction after those doing the extraction have moved on (Hornborg 2009).

Impoverished systems tend to be highly resilient (Carpenter and Brock 2008), both because degraded ecosystems are resilient and because people have become so dependent on the few resources that are available, that they must harvest those resources even when doing so maintains their degraded state (Brashares et al. 2004; Nayak et al. 2014; Loring 2016). This pattern has been described in the resilience literature as a poverty trap and in political ecology as the marginalization-degradation feedback loop (Carpenter and Brock 2008; Robbins 2012). Impoverished systems also exhibit tight couplings between livelihoods and the few resources available. For example, Brashares and colleagues (2004) show that bushmeat hunting patterns in West Africa were tightly coupled to the availability of fish-people increased hunting when fish supplies were sparse and vice versa.

Impoverished food systems are a ubiquitous legacy of the extractive practices of colonialism and industrial capitalism around the world (Hornborg 2009). For example, Nayak and colleagues (2014) show how resource extraction by elites and for industrial fisheries in India and Brazil has instigated this mutually reinforcing trap through a combination of disempowerment, marginalization, class exploitation, and economic exclusion. Because impoverished systems create perverse economic incentives for people to further degrade those systems, restoring regenerative capacity of impoverished systems must start first with improving local livelihoods, for example through immediate subsidies, reparations, and local development based on ecological restoration (Cao et al. 2009).

\section{Regime 4: coerced}

Coerced regimes entail a combination of rigid livelihood strategies and ecological uniformity (Fig. 2d). Unlike impoverished systems, however, in a coerced system the lack of diversity is not the result of degradation but of active cultivation, in that strategic actions are taken to favor and maintain the abundance of only one or a few highly valued key resources (Cassano et al. 2009; R. S Steneck et al. 2011; Borkhataria et al. 2012; Angeler et al. 2020). Because people are actively promoting the success of these resources over others, systems that were previously diverse and regenerative become progressively simple, i.e., monocultures, and the social institutions that develop around the success of these monocultures become extremely robust (Henry and Johnson 2015; Angeler et al. 2020). While coerced systems can gain a reputation for their sustainability (Acheson 1975; Henry and Johnson 2015), all of their regenerative potential is tied up in maintaining the prized resources. As such, while these systems can be lucrative, they are vulnerable to disruption, prone to boom-and-bust dynamics, and difficult to change (Clough et al. 2009; Barbier 2020). Coerced systems can also be prone to path dependence, where past decisions significantly constrain future adaptability (Cox et al. 2019).

Some coerced systems have been described as a "gilded trap" (R. S Steneck et al. 2011). Examples include rice, cacao, and coffee production in Latin America and lobster fisheries in Maine (Cassano et al. 2009; R. S Steneck et al. 2011; Borkhataria et al. 2012; Cox et al. 2019). Maine lobster fisheries, for example, have long been hailed as sustainability success stories and are well known for the many customary practices and informal institutions that have enabled fishers to effectively convert the Gulf of Maine ecosystem into a lobster monoculture (Acheson 1990). Top predators are all but absent from the marine foodweb (Robert S. Steneck and Wahle 2013), and a significant proportion 
of lobsters' diet now comes from baitfish rather than wild, predated fish (Grabowski et al. 2010). Economic diversity among Maine fishers is also at a historic low (Steneck et al 2011). Thus, the fishery and fishing communities alike face unprecedented vulnerability to ecological challenges like climate warming and disease, as well as to economic stressors like recession and market disruptions like COVID-19 (R. S Steneck et al. 2011; Henry and Johnson 2015).

Cox and colleagues (2019) found a very similar set of circumstances in the coerced rice farming regime in the Dominican Republic: a highly productive system that is cultivated for its uniformity and that, as such, requires extensive capitalization and external inputs. What this case adds to the present discussion is the role of path dependence in the emergence of coerced regimes, in that local people become progressively locked into specific actions that reinforce the regime. In the case of the Dominican Republic, this has included a pipeline of farmer debt, negative impacts of rice farming practices on the surrounding ecosystems, and the build-up of finance, subsidies, and technical governmental assistance around rice production to the exclusion of other agricultural possibilities.

\section{Discussion}

While relatively straightforward in its construction, this framework can be applied to explore food systems at any number of organizational levels, from the resource strategies and portfolios of individual households, farmers, or fishers, to community- and regional-level patterns of resource use and coordination. At question in any such exploration is the disposition of the system towards change: whether people seek to conserve change, by working with natural cycles of variability and by adopting strategies that are flexible, responsive, and that promote diversity, or if they seek to fight change in favor of the stability of one or a few valued resources at the expense of other aspects of the living system.

Critical here is the recognition that it is not the specific technologies or practices, per se, that make a food system regenerative. While some technologies, like herbicides and pesticides are arguably predisposed towards achieving stability and uniformity, many food production practices could theoretically be encountered in any of the four regimes. Grazing and shifting cultivation, for example, have been a part of both degenerative and regenerative regimes, and the contrasts between these are instructive for understanding the conservation of change principle. In both cases, their outcomes depend on people's flexibility and responsiveness to environmental change, and whether people are taking steps to isolate or integrate their food production practices with the surrounding landscape and cycles of change therein
(Savory 1988; Padoch and Pinedo-Vasquez 2010). Shifting cultivation was not only regenerative but enriching to the Amazon biome when people practiced it in a way that was fully integrated into all stages of the forest's successional system. The same is true for the Burren winterage, in which grazing is enhancing a long-degraded landscape because the system is organized to attend not only to the needs of people and the cattle, but the seasonal needs of the landscape.

Differentiating among regenerative and coerced systems can be particularly challenging because the latter generally emerges from the former, and can be maintained as sustainable, at least for a time. To identify whether a system is moving from regenerative to coerced regimes requires attention to historical trajectories of development as well as to some of the hallmarks of coerced systems explored above, including declines in ecological health and biodiversity, and evidence of emerging path dependence, such as debt pipelines, industry consolidation, and build-up of subsidies around individual, high-value resources. The similarities among regenerative and early-stage coerced regimes is particularly noteworthy because it could be exploited by firms seeking to capitalize on consumer interest in regenerative practices despite perpetuating a system that is, in fact, extractive and harmful.

The disposition of feedbacks and power are two additional ways that the four regimes can be differentiated. Feedbacks describe the quality of information moving to and from social and ecological components of the system (Sundkvist et al. 2005). Examples of feedbacks include a hunter or fisher seeing direct evidence of population decline, or a consumer's use of labeling and traceability to ensure coffee farmers receive a fair wage and conduct responsible farming practices. Power, likewise, refers to whether people are free to respond and adapt to environmental feedbacks as they see fit. People may not have the ability to choose alternatives in response to feedbacks, for example because of rigid markets, overly complex supply chains, oppressive political regimes, exclusionary pricing, or systems of command-and-control governance that are less sensitive to local environmental and social circumstances (Lang 2003; Clapp and Fuchs 2009).

In regenerative systems people rely on tight feedbacks, and they need the power to observe, experiment, and adjust their actions in response to indicators of environmental change. Indigenous food systems, for example, which often involve complex seasonal calendars of practices and a large portfolio of alternatives, rely heavily on ecological knowledge and sustained environmental observation (Berkes 2008). In impoverished regimes, feedbacks may exist, but people may not have access or the power to choose alternatives, whether because environmental degradation has eliminated alternatives or because the alternatives that do exist are economically or politically reserved for elites. In degenerative systems, feedbacks are either hidden, ignored, 
or misunderstood; historical examples of overfishing, for example, was in part a result of a cultural assumption that fish stocks would be infinitely replenished. In coerced systems, cultural values and availability of cheap subsidies can lead harvesters to ignore feedbacks that signal increased vulnerability of the system at large, while the progressive consolidation of control and wealth also restricts producers from exploring alternatives and limits consumers' ability to influence decisions regarding how their food is produced.

A final way that the four regimes differ is the role of resilience. In regenerative systems, there is an ongoing give and take of resilience, in that at times, people draw resilience from ecosystems, while at others they impart resilience to ecosystems through their willingness to be flexible and promote diversity (Fig. 3). In degenerative systems, by comparison, wealth is extracted until ecosystems can give no more and people move on to whatever will provide a viable substitute. Ecosystems in degenerative regimes continue to provide resilience for social systems, but as entropy increases, the resilience and regenerative potential of the system is eroded and diversity declines. Coerced systems have a similar pattern, except that human actions are designed to impose structure by way of ecosystem simplification and the introduction of subsidies to enhance production of the desired resource. Finally, impoverished systems are highly resilient for their lack of natural and social capital, which creates a reinforcing pattern that keeps entropy high, and hence, regenerative potential low.

\section{Pathways to regenerative systems}

Understanding how degenerative, coerced, and impoverished regimes come to be, and what keeps them stable despite their diminished entropic capacity, is key to identifying pathways to achieving regenerative food futures (Table 1). There is likely no uniform progression of food systems through the four regimes, though transitions away from regenerative systems is arguably the most common trajectory seen in the last century, driven by a mix of colonialism, modernist ideology, and the rapid deployment of technologies in service of neoliberal capitalism and the Global North (Hickel et al. 2021; Loring and Sanyal 2021). Exploring such a transition in the Netherlands, Geels (2009) shows how a dramatic transition from diverse, mixed farming systems to industrial

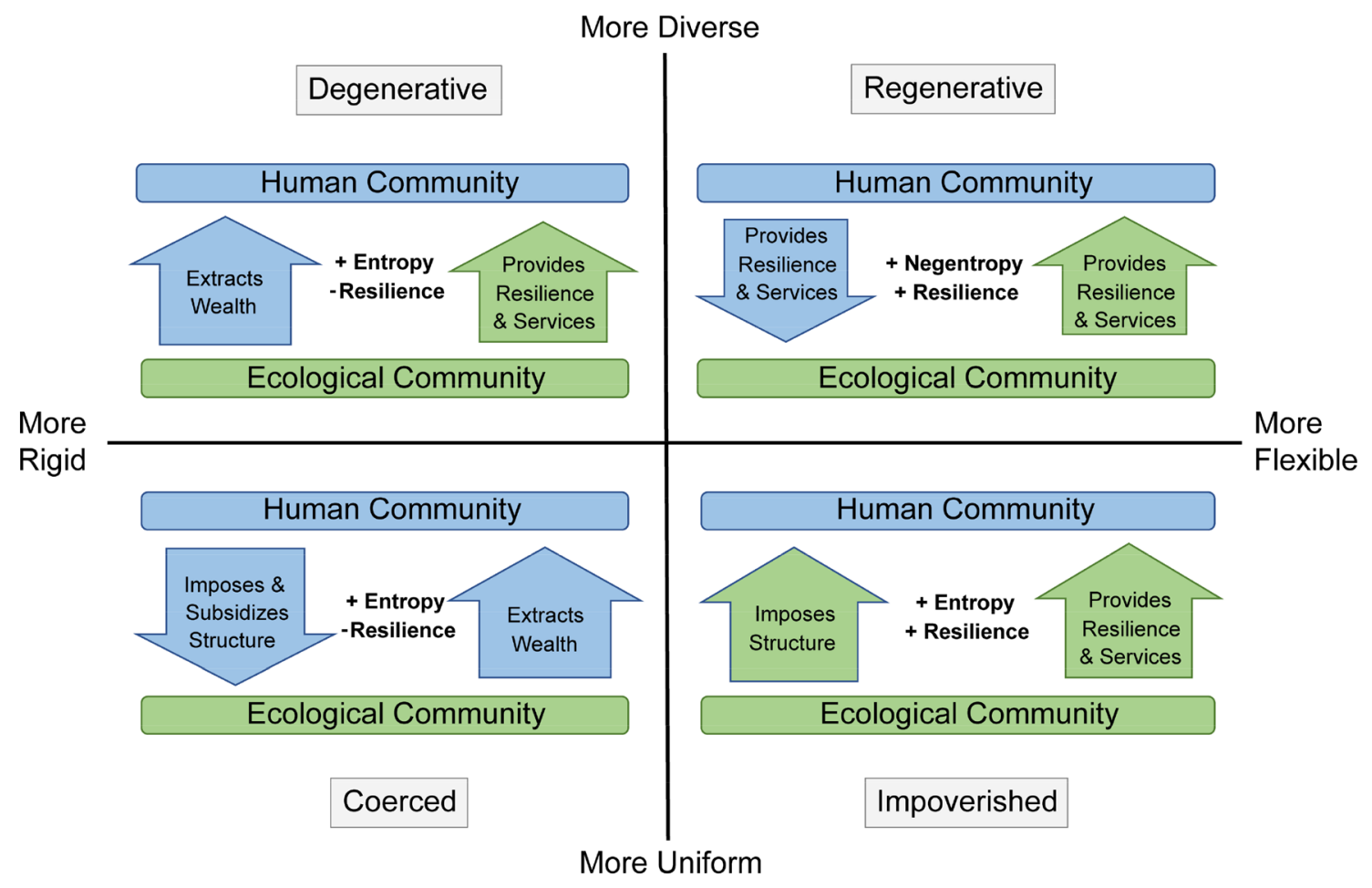

Fig. 3 The interplay between resilience and entropy or negentropy in the four regimes. Regenerative systems generate shared wealth via a give and take of resilience; in some cases, people draw resilience from ecosystems, in other cases they impart it by altering their strategies in response to environmental feedbacks. Degenerative systems extract wealth with little concern for the status of resources and are resilient because they readily exploit alternatives when resources are overharvested. Coerced systems make great investments to impose and sustain structure to enable the continued extraction of wealth from a single highly valued resource but reduce resilience over time. In impoverished systems, wealth has been previously extracted and entropy is high, which also results in high, but maladaptive resilience (i.e., the poverty trap) 
Table 1 Pathways to regenerative food systems, with a focus on strategies identified in key citations

\begin{tabular}{|c|c|c|c|}
\hline Current regime & Possible stabilizing features & Key citations & Transformative actions \\
\hline $\begin{array}{l}\text { Degenerative - "Eating down } \\
\text { food webs" }\end{array}$ & $\begin{array}{l}\text { Strong, established markets } \\
\text { Rigid consumer expectations } \\
\text { Lax regulation } \\
\text { Availability of substitutes } \\
\text { Weak environmental feedbacks } \\
\text { Disregard for environmental } \\
\text { feedbacks }\end{array}$ & $\begin{array}{l}\text { (Pauly et al. 1998; Essington et al. } \\
\text { 2006; Stergiou et al. 2009) }\end{array}$ & $\begin{array}{l}\text { Market diversification } \\
\text { Catch limits or closures } \\
\text { Foster a culture of variability } \\
\text { Strengthen social-ecological feed- } \\
\text { backs across supply chain } \\
\text { Restore depleted species as possible }\end{array}$ \\
\hline $\begin{array}{l}\text { Impoverished - "The Poverty } \\
\text { Trap" or "Marginalization- } \\
\text { degradation" feedback }\end{array}$ & $\begin{array}{l}\text { Degraded ecosystems } \\
\text { Elite capture of power \& capital } \\
\text { Weak institutions } \\
\text { Conflict }\end{array}$ & $\begin{array}{l}\text { (Carpenter and Brock 2008; Cao } \\
\text { et al. 2009; Robbins 2012; } \\
\text { Nayak et al. 2014; Loring 2016) }\end{array}$ & $\begin{array}{l}\text { Fund ecological restoration } \\
\text { Social reconciliation } \\
\text { Invest in local food system infra- } \\
\text { structure } \\
\text { Return land and reform/restore } \\
\text { property rights } \\
\text { Incentivize pro-biodiversity actions }\end{array}$ \\
\hline Coerced - "The Gilded Trap" & $\begin{array}{l}\text { Strong, established markets } \\
\text { High market value } \\
\text { Availability of cheap subsidies } \\
\text { Strong institutions } \\
\text { Simplified ecosystems } \\
\text { Reduced adaptive capacity }\end{array}$ & $\begin{array}{l}\text { (R. S Steneck et al. 2011; Henry } \\
\text { and Johnson 2015; Cox et al. } \\
\text { 2019; Angeler et al. 2020) }\end{array}$ & $\begin{array}{l}\text { Divert subsidies for ecological } \\
\text { restoration \& market re-diversi- } \\
\text { fication } \\
\text { Empower harvesters for collective } \\
\text { action to experiment with alterna- } \\
\text { tives } \\
\text { Gear buy-backs } \\
\text { Incentivize new entry to emerging } \\
\text { alternatives }\end{array}$ \\
\hline
\end{tabular}

hog farming resulted not simply as a result of technological innovation or farmers making rational decisions, but from a complicated interplay of social narratives of progress, government policies and land rationalization, technological developments, and the rise and influence of supermarkets, to name some of the major factors. Similarly, Clapp (2021) shows that a mix of technology, market, corporate, and state regulatory forces, together with coordinated exclusion of alternative pathways, were responsible for the widespread global transition to chemical herbicide-centric cropping practices. Examples are also numerous where degenerative colonial regimes of resource extraction have collapsed, leaving behind impoverished systems in which local people are locked into precarious dependence on sparse local resources and external aid (Sen 1983; Nayak et al. 2014).

There are also some examples where improvements in science and technology, coupled with sufficient social and economic incentives, have enable transitions away from degenerative regimes. Fisheries are a ready example; improvements in fisheries science and monitoring, together with privatization in the forms of quotas, growing demand for sustainable practices, and proliferation of certification schemes, have been extremely effective at slowing the "fishing down the foodweb" pattern and enhancing and stabilizing individual, high-value fish stocks (Hilborn et al. 2020). However, continued oceanwide declines in marine biodiversity and biomass suggest that, while sustainable, at least some of these fisheries may be more accurately described as coerced rather than regenerative (Palomares et al. 2020;
Pimiento et al. 2020). The widespread societal pattern of disenfranchisement and injustice that has accompanied these socio-technical transitions in sustainable fisheries further substantiates this assessment (Pinkerton and Davis 2015; Bennett et al. 2021).

Moving into a regenerative regime represents likely the most difficult pathway for transformation. Sociotechnical regimes like food systems are generally conservative in nature (Lawhon and Murphy 2012), which means that there are internal stabilizing processes and features that keep these regimes functioning despite their numerous problems: subsidies, the ability to export and mask environmental damage, and the power to coerce and constrain people from seeking alternatives are three examples. Initiatives for systemic change need to confront these stabilizing system dynamics at least as much as they address practices that work directly against the conservation of change principle. This means attending to the history of how these systems have developed and the imbalances and injustices that have emerged as a result. Likewise, this means that technological innovations, on their own, are unlikely to be sufficient to spur regime change unless they disrupt existing distributions of power.

Because strong institutions and path dependence often feature into existing food production regimes, new forms of collective action and disruptive innovation are necessary to move global food systems towards regenerative alternatives. Alternative food movements exist in the shadow of the dominant regime, which means they are necessarily at a structural disadvantage (Lawhon and Murphy 2012; Hoey 
and Sponseller 2018). As such, emerging food systems innovations can benefit from systemic disruptions to the status quo before they find the necessary niche space to thrive. For example, alternative food movements such as community supported agriculture and fisheries thrived during the first 18 months of the COVID-19 pandemic, while global food supply chains faltered (Stoll et al. 2021; Thilmany et al. 2021). Extra support for these innovations, by way of social finance, exemptions from restrictive policies and regulations, and access to platforms and opportunities for collaboration, can also be critical to increasing niche space and facilitating planned transitions to regenerative food systems (Salatin 2007; Stephens and Clapp 2020).

Strategies to achieving regenerative food systems must also be restorative and retributive in nature-not merely a swapping out of new practices for old-but designed to address and compensate for past social and ecological harms while also devoting sufficient resources to restore local biodiversity and social capital (Lam and Pitcher 2012; Ikerd 2021). If people are locked into impoverished systems, for example, immediate aid and relief is necessary to enable people to take pressure off depleted resources. But, this aid must be coupled with active ecological restoration and sufficient social and political reform to ensure that people are empowered to rebuild and develop adaptive strategies based on local ecological knowledge and tight social-ecological feedbacks (Sundkvist et al. 2005; Cao et al. 2009).

\section{Conclusion}

We face critical environmental, climatic, and societal challenges related to our food systems. Debates over how best to define, implement, and scale out solutions are important, but rigid policing of concepts like regenerative agriculture can be counter to the pluralism that is truly necessary for developing food systems that work for local people, places, and cultures. Here, I offer a framework that establishes clear and meaningful patterns in how food systems are organized and how these patterns relate to ecological, and to a lesser extent societal, outcomes. This framework, and the conservation of change principle upon which it rests, are a novel application of principles drawn from thermodynamics and grounded in numerous real-world examples that can be used to understand existing food systems challenges and plan for future food systems transitions. The framework is generally agnostic regarding the specifics of the practices and technologies being implemented, which leaves space for pluralism in how people relate to the land, sea, and their neighbours through food.

Conserving change, as a principle for achieving food systems that are sustainable, equitable, and just, is thus not just a technological challenge but a cultural reorientation in which we adapt our livelihoods and reorient our perception of value to fully acknowledge the generative contributions of the natural world to our lives. Many Indigenous and peasant communities already understand, embody, and practice this perspective, and I believe that the widespread and growing interest in radically changed food systems indicates that this reorientation is underway in the grassroots of food systems around the world.

Next steps in research on regenerative food systems could further test the conservation of change framework through empirical studies and meta-analysis or systematic reviews. There may well be important caveats or counterfactuals to be discovered that can help to further develop guidance for organizing food systems to achieve regenerative outcomes. This is certainly true for issues of power and equity; it may not be the case that all regenerative systems will necessarily support outcomes such as social and environmental justice, though my working hypothesis is that they will. Still, the framework offered here is clearly situated in the human ecology of food systems, so while it does begin to capture issues such as power, marginalization, and capacity, more research and theorization are called for to explore the political ecology of these regimes and the possible pathways and necessary conditions for achieving systems that are not only regenerative but equitable and just as well.

Acknowledgements This work was funded in part by the Arrell Food Institute at the University of Guelph.

\section{References}

Acheson, James M. 1975. The Lobster Fiefs: Economic and Ecological Effects of Territoriality in the Maine Lobster Industry. Human Ecology 3: 183-207.

Acheson, James M. (1990) The Lobster Fiefs Revisited. In Question of the commons, ed. Bonnie J. McCay and James L. Anderson. Tuscon: The University of Arizona Press

Angeler, David, Brian C. Chaffin, Shana M. Sundstrom, Ahjond Garmestani, Kevin L. Pope, Daniel R. Uden, Dirac Twidwell, and Craig R. Allen. 2020. Coerced regimes: management challenges in the Anthropocene. Ecology and Society. https://doi.org/ 10.5751/ES-11286-250104.

Barbier, Edward B. 2020. Long run agricultural land expansion, booms and busts. Land Use Policy 93. Elsevier: 103808.

Bogaard, Amy, Dragana Filipović, Andrew Fairbairn, Laura Green, Elizabeth Stroud, Dorian Fuller, and Michael Charles. 2017. Agricultural innovation and resilience in a long-lived early farming community: the 1,500-year sequence at Neolithic to early Chalcolithic Çatalhöyük, central Anatolia. Anatolian Studies 67. Cambridge University Press: 1-28.

Beaudreau, Anne H., Eric J. Ward, Richard E. Brenner, Andrew O. Shelton, Jordan T. Watson, Jennifer C. Womack, Sean C. Anderson, Alan C. Haynie, Kristin N. Marshall, and Benjamin C. Williams. 2019. Thirty years of change and the future of Alaskan fisheries: Shifts in fishing participation and diversification in response to environmental, regulatory and economic pressures. Fish and Fisheries 20: 601-619. 
Bennett, Nathan James, Jessica Blythe, Carole Sandrine White, and Cecilia Campero. 2021. Blue growth and blue justice: Ten risks and solutions for the ocean economy. Marine Policy 125: 104387.

Berkes, Fikret. 2008. Sacred ecology, 2nd ed. London, UK: Taylor \& Francis.

Bernhardt, Joey R., and Mary I. O'Connor. 2021. Aquatic biodiversity enhances multiple nutritional benefits to humans. Proceedings of the National Academy of Sciences of the United States of America 18 (15): e1917787118.

Borkhataria, Rena, Jaime A. Collazo, Martha J. Groom, and Adrian Jordan-Garcia. 2012. Shade-grown coffee in Puerto Rico: Opportunities to preserve biodiversity while reinvigorating a struggling agricultural commodity. Agriculture, Ecosystems \& Environment 149: 164-170.

Born, B., and M. Purcell. 2006. Avoiding the local trap: scale and food systems in planning research. J Plann Edu Res 26: 195-207.

Brady, Nyle C. 1996. Alternatives to slash-and-burn: A global imperative. Agriculture, Ecosystems \& Environment 58: 3-11.

Brashares, Justin S., Peter Arcese, Moses K. Sam, Peter B. Coppolillo, A.R.E. Sinclair, and Andrew Balmford. 2004. Bushmeat Hunting, Wildlife Declines, and Fish Supply in West Africa. Science 306: 1180-1183.

Campbell, Bruce M., Douglas J. Beare, Elena M. Bennett, Jason M. Hall-Spencer, John S. I. Ingram, Fernando Jaramillo, Rodomiro Ortiz, Navin Ramankutty, Jeffrey A. Sayer, and Drew Shindell. 2017. Agriculture production as a major driver of the Earth system exceeding planetary boundaries. Ecology and Society. https://doi.org/10.5751/ES-09595-220408.

Cao, S., B. Zhong, H. Yue, H. Zeng, and J. Zeng. 2009. Development and testing of a sustainable environmental restoration policy on eradicating the poverty trap in China's Changting County. Proc Nat Academy Sci 106: 10712-10716.

Carlisle, Liz. 2014. Diversity, flexibility, and the resilience effect: lessons from a social-ecological case study of diversified farming in the northern Great Plains. USA: Ecology and Society. https:// doi.org/10.5751/ES-06736-190345.

Carpenter, S., and J.H. Brock. 2008. Adaptive Capacity and Traps. Ecology and Society 13: 40.

Cassano, Camila R., Götz. Schroth, Deborah Faria, Jacques H. C. Delabie, and Lucio Bede. 2009. Landscape and farm scale management to enhance biodiversity conservation in the cocoa producing region of southern Bahia, Brazil. Biodiversity and Conservation 18: $577-603$.

Chase, Jonathan M., and Mathew A. Leibold. 2002. Spatial scale dictates the productivity-biodiversity relationship. Nature 416 : 427-430.

Cinner, Joshua E., W. Neil Adger, Edward H. Allison, Michele L. Barnes, Katrina Brown, Philippa J. Cohen, Stefan Gelcich, et al. 2018. Building adaptive capacity to climate change in tropical coastal communities. Nature Climate Change 8: 117-123.

Clapp, Jennifer. 2021. Explaining growing glyphosate use: the political economy of herbicide-dependent agriculture. Global Environmental Change 67: 102239.

Clapp, Jennifer, and Doris A. Fuchs. 2009. Corporate Power in Global Agrifood Governance. MIT Press.

Clough, Yann, Heiko Faust, and Teja Tscharntke. 2009. Cacao boom and bust: Sustainability of agroforests and opportunities for biodiversity conservation. Conservation Letters 2: 197-205.

Cox, Michael, Frederick Payton, and Leoncio Pimentel. 2019. A gilded trap in Dominican rice farming. Land Use Policy 80: 10-20.

Dunford, Brendan. 2002. Farming and the Burren. Vol. 19. Teagasc: Dublin.

Ellis, Erle C., Nicolas Gauthier, Kees Klein Goldewijk, Rebecca Bliege Bird, Nicole Boivin, Sandra Díaz, Dorian Q. Fuller, Jacquelyn L. Gill, Jed O. Kaplan, and Naomi Kingston. 2021. People have shaped most of terrestrial nature for at least 12,000 years. Proceedings of the National Academy of Sciences 118: 2023483118

England, Jeremy L. 2013. Statistical physics of self-replication. The Journal of Chemical Physics 139: 121923.

Eriksen, Safania Normann. 2013. Defining local food: constructing a new taxonomy - three domains of proximity. Acta Agriculturae Scandinavica, Section B - Soil \& Plant Science 63: 47-55

Essington, Timothy E., Anne H. Beaudreau, and John Wiedenmann. 2006. Fishing Through Marine Food Webs. Proceedings of the National Academy of Sciences of the United States of America 103: 3171-3175.

Fisher, Julia A., Nancy Shackelford, Morgan D. Hocking, Andrew J. Trant, and Brian M. Starzomski. 2019. Indigenous peoples' habitation history drives present-day forest biodiversity in British Columbia's coastal temperate rainforest. People and Nature 1: $103-114$.

Fjeldsaå, Jon, and Jon C. Lovett. 1997. Biodiversity and environmental stability. Biodiversity \& Conservation 6: 315-323.

Ford, Anabel, and Ronald Nigh. 2015. The Maya forest garden: Eight millennia of sustainable cultivation of the tropical woodlands, 1st ed. Walnut Creek, California: Routledge.

Francis, Charles A., Richard R. Harwood, and James F. Parr. 1986. The potential for regenerative agriculture in the developing world. American Journal of Alternative Agriculture 1: 65-74.

Fraser, Evan D. G., and Malcolm Campbell. 2019. Agriculture 5.0: Reconciling Production with Planetary Health. One Earth 1: 278-280.

Fraser, Evan D. G., W. Mabee, and F. Figg. 2005. A framework for assessing the vulnerability of food systems to future shocks. Futures 37: 465-479.

Fraser, Evan D. G., K.C. Alexander Legwegoh, Mike CoDyre. Krishna, Goretty Dias, Shelley Hazen, Rylea Johnson, Ralph Martin, Lisa Ohberg, and Sri Sethuratnam. 2016. Biotechnology or organic? Extensive or intensive? Global or local? A critical review of potential pathways to resolve the global food crisis. Trends in Food Science \& Technology 48: 78-87.

Garnett, Tara, Michael C. Appleby, Andrew Balmford, Ian J. Bateman, Tim G. Benton, Phil Bloomer, Barbara Burlingame, Marian Dawkins, Liam Dolan, and Evan D. G. Fraser. 2013. Sustainable intensification in agriculture: premises and policies. Science 341: 33-34.

Geels, Frank W. 2009. Foundational ontologies and multi-paradigm analysis, applied to the socio-technical transition from mixed farming to intensive pig husbandry (1930-1980). Technology Analysis \& Strategic Management 21: 805-832.

Giller, Ken E., Renske Hijbeek, Jens A. Andersson, and James Sumberg. 2021. Regenerative Agriculture: An agronomic perspective. Outlook on Agriculture 50: 13-25.

Grabowski, Jonathan H., Erika J. Clesceri, Adam J. Baukus, Julien Gaudette, Matthew Weber, and Philip O. Yund. 2010. Use of Herring Bait to Farm Lobsters in the Gulf of Maine. PLoS ONE 5: e10188.

Gunderson, Lance H., and C. S. Holling. 2002. Panarchy: understanding transformations in human and natural systems. Island Press.

Henry, Anna M., and Teresa R. Johnson. 2015. Understanding social resilience in the maine lobster industry. Marine and Coastal Fisheries 7: 33-43.

Hickel, Jason, Dylan Sullivan, and Huzaifa Zoomkawala. 2021. Plunder in the post-colonial era: quantifying drain from the global south through unequal exchange, 1960-2018. New Political Economy 1: $1-18$.

Hilborn, Ray, Ricardo Oscar Amoroso, Christopher M. Anderson, Julia K. Baum, Trevor A. Branch, Christopher Costello, Carryn L. de Moor, et al. 2020. Effective fisheries management instrumental in improving fish stock status. Proceedings of the National Academy of Sciences 117: 2218-2224. 
Hoey, Lesli, and Allison Sponseller. 2018. "It's hard to be strategic when your hair is on fire": Alternative food movement leaders' motivation and capacity to act. Agriculture and Human Values 35: 595-609.

Holt-Giménez, Eric, Annie Shattuck, Miguel Altieri, Hans Herren, and Steve Gliessman. 2012. We already grow enough food for 10 billion people ... and still can't end hunger. Journal of Sustainable Agriculture 36: 595-598.

Hooper, D.U., F.S. Chapin, J.J. Ewel, A. Hector, P. Inchausti, S. Lavorel, J.H. Lawton, et al. 2005. Effects of biodiversity on ecosystem functioning: a consensus of current knowledge. Ecological Monographs 75: 3-35.

Hornborg, A. 2009. Zero-Sum World: Challenges in conceptualizing environmental load displacement and ecologically unequal exchange in the world system. International Journal of Comparative Sociology 50: 237-262.

Ikerd, John. 2021. THE ECONOMIC PAMPHLETEER: Realities of regenerative agriculture. Journal of Agriculture, Food Systems, and Community Development 10: 1-4.

IPES-Food. 2020. The added value(s) of agroecology: Unlocking the potential for transition in West Africa. Brussels, Belgium: International Panel of Experts on Sustainable Food Systems.

Katz-Rosene, Ryan M. 2020. "Ditch red meat and dairy, and don't bother with local food": The problem with universal dietary advice aiming to save the planet (and your health). Canadian Food Studies / La Revue Canadienne Des Études Sur L'alimentation 7: 5-19.

Kleinman, P.J.A., D. Pimentel, and R.B. Bryant. 1995. The ecological sustainability of slash-and-burn agriculture. Agriculture, Ecosystems \& Environment 52: 235-249.

Kloppenburg, J., J. Hendrickson, and G.W. Stevenson. 1996. Coming into the Foodshed. Agriculture and Human Values 13: 33-42.

Kottak, Conrad P. 1990. Culture and "economic development." American Anthropologist 92: 723-732.

LaCanne, Claire E., and Jonathan G. Lundgren. 2018. Regenerative agriculture: merging farming and natural resource conservation profitably. PeerJ 6: e4428

Lam, Mimi E., and Tony J. Pitcher. 2012. The ethical dimensions of fisheries. Current Opinion in Environmental Sustainability 4: 364-373.

Lang, Tim. 2003. Food industrialisation and food power: implications for food governance. Development Policy Review 21: 555-568.

Lawhon, Mary, and James T. Murphy. 2012. Socio-technical regimes and sustainability transitions: Insights from political ecology. Progress in Human Geography 36: 354-378.

Loring, Philip A. 2016. The political ecology of gear bans in two fisheries: Florida's net ban and Alaska's Salmon wars. Fish and Fisheries 18: 94-104.

Loring, Philip A. 2020a. Threshold concepts and sustainability: Features of a contested paradigm. FACETS 5: 182-199.

Loring, Philip A. 2020b. Finding our niche: Toward a restorative human ecology. Halifax, NS: Fernwood Publishing.

Loring, Philip A., and S. Craig Gerlach. 2010. Outpost gardening in interior alaska: food system innovation and the alaska native gardens of the 1930s through the 1970s. Ethnohistory 57: 183-199.

Loring, Philip A., and Palash Sanyal. In press. Indicators of Complexity and Over-complexification in Global Food Systems. Frontiers in Sustainable Food Systems.

Mulumba, J.W., R. Nankya, J. Adokorach, C. Kiwuka, C. Fadda, P. De Santis, and D.I. Jarvis. 2012. A risk-minimizing argument for traditional crop varietal diversity use to reduce pest and disease damage in agricultural ecosystems of Uganda. Agriculture, Ecosystems \& Environment 157: 70-86.

Nayak, Prateep K., Luiz E. Oliveira, and Fikret Berkes. 2014. Resource degradation, marginalization, and poverty in small-scale fisheries: Threats to social-ecological resilience in India and Brazil. Ecology and Society 19: 73.

Newton, Peter, Nicole Civita, Lee Frankel-Goldwater, Katharine Bartel, and Colleen Johns. 2020. What is regenerative agriculture? A review of scholar and practitioner definitions based on processes and outcomes. Frontiers in Sustainable Food Systems 4: 194.

O'Rourke, Eileen. 2005. Socio-natural interaction and landscape dynamics in the Burren, Ireland. Landscape and Urban Planning 70: 69-83.

Oliveira, Edmar Almeida, and de, Ben Hur Marimon-Junior, Beatriz Schwantes Marimon, José Iriarte, Paulo S. Morandi, S. Yoshi Maezumi, Denis S. Nogueira, Luiz E. O. C. Aragão, Izaias Brasil da Silva, and Ted R. Feldpausch. 2020. Legacy of Amazonian Dark Earth soils on forest structure and species composition. Global Ecology and Biogeography 29: 1458-1473.

Padoch, Christine, and Miguel Pinedo-Vasquez. 2010. Saving Slashand-Burn to Save Biodiversity. Biotropica 42: 550-552.

Palomares, M.L.D., R. Froese, B. Derrick, J.J. Meeuwig, S.-L. Nöel, G. Tsui, J. Woroniak, D. Zeller, and D. Pauly. 2020. Fishery biomass trends of exploited fish populations in marine ecoregions, climatic zones and ocean basins. Estuarine, Coastal and Shelf Science 243: 106896.

Pauly, Daniel, Villy Christensen, Johanne Dalsgaard, Rainer Froese, and Francisco Torres. 1998. Fishing down marine food webs. Science 279: 860-863.

Penca, Jerneja. 2019. Transnational localism: empowerment through standard setting in small-scale fisheries transnational. Environmental Law 8 (143): 165. https://doi.org/10.1017/S204710251 8000328.

Pereira, Laura, Rachel Wynberg, and Yuna Reis. 2018. Agroecology: The future of sustainable farming? Environment: Science and Policy for Sustainable Development 60: 4-17.

Pimiento, C., F. Leprieur, D. Silvestro, J.S. Lefcheck, C. Albouy, D.B. Rasher, M. Davis, J.-C. Svenning, and J.N. Griffin. 2020. Functional diversity of marine megafauna in the Anthropocene. Science Advances 6: 7650.

Pimm, Stuart L. 1984. The complexity and stability of ecosystems. Nature 307: 321-326.

Pinkerton, Evelyn, and Reade Davis. 2015. Neoliberalism and the politics of enclosure in North American small-scale fisheries. Marine Policy 61: 303-312.

Rapport, D.J., R. Costanza, and A.J. McMichael. 1998. Assessing ecosystem health. Trends in Ecology \& Evolution 13: 397-402.

Reganold, John P., and Jonathan M. Wachter. 2016. Organic agriculture in the twenty-first century. Nature Plants 2: 15221.

Renard, Delphine, and David Tilman. 2019. National food production stabilized by crop diversity. Nature 571: 257-260.

Rhodes, Christopher J. 2017. The imperative for regenerative agriculture. Science Progress 100: 80-129.

Rist, L., A. Felton, M. Nyström, Max Troell, Ryan A. Sponseller, J. Bengtsson, H. Österblom, P. Regina Lindborg, and Tidåker, and D. G. Angeler. 2014. Applying resilience thinking to production ecosystems. Ecosphere 5: 1-11.

Robbins, Paul. 2012. Political Ecology: A Critical Introduction. New York, NY: John Wiley \& Sons.

Rockström, Johan, Ottmar Edenhofer, Juliana Gaertner, and Fabrice DeClerck. 2020. Planet-proofing the global food system. Nature Food 1: 3-5.

Rotz, Sarah, Emily Duncan, Matthew Small, Janos Botschner, Rozita Dara, Ian Mosby, Mark Reed, and Evan D. G. Fraser. 2019. The politics of digital agricultural technologies: a preliminary review. Sociologia Ruralis 59: 203-229.

Salatin, Joel. 2007. Everything I want to do is illegal: War stories from the local food front. Hartford, VT: Chelsea Green Publishing Company. 
Saunders, Caroline, and Andrew Barber. 2008. Carbon footprints, life cycle analysis, food miles: Global trade trends and market issues. Political Science 60: 73-88.

Savory, A. 1988. Holistic resource management. Washington, D.C.: Island Press.

Schreefel, L., R.P.O. Schulte, I.J.M. de Boer, A. Pas Schrijver, and H.H.E. van Zanten. 2020. Regenerative agriculture - the soil is the base. Global Food Security 26: 100404.

Sen, Amartya. 1983. Poverty and Famines: An Essay on Entitlement and Deprivation. Oxford, UK: Oxford University Press.

Steneck, Robert S., and Richard A. Wahle. 2013. American lobster dynamics in a brave new ocean. Canadian Journal of Fisheries and Aquatic Sciences 70: 1612-1624.

Steneck, R.S., T.P. Hughes, Joshua E. Cinner, W. Neil Adger, S.N. Arnold, S.A. Fikret Berkes, Boudreau, et al. 2011. Creation of a gilded trap by the high economic value of the maine lobster fishery. Conservation Biology 25: 904-912. https://doi.org/10. 1111/j.1523-1739.2011.01717.x.

Stephens, Phoebe, and Jennifer Clapp. 2020. Financing food system regeneration?: The potential of social finance in the agrifood sector. In Routledge handbook of sustainable and regenerative food systems Routledge New York NY Pp.1-14

Stergiou, Konstantinos I., Athanassios C. Tsikliras, and Daniel Pauly. 2009. Farming up Mediterranean Food Webs. Conservation Biology 23: 230-232.

Stoll, Joshua S., Hannah L. Harrison, Emily De Sousa, Debra Callaway, Melissa Collier, Kelly Harrell, Buck Jones, et al. 2021. Alternative seafood networks during COVID-19: implications for resilience and sustainability. Frontiers in Sustainable Food Systems 5: 614368.

Sundkvist, A., R. Milestad, and A. Jansson. 2005. On the importance of tightening feedback loops for sustainable development of food systems. Food Policy 30: 224-239.

Sutton, Michael. 1996. The Marine Stewardship Council: New hope for marine fisheries. Naga, the ICLARM Quarterly 19: 10-12.

Thilmany, Dawn, Elizabeth Canales, Sarah A. Low, and Kathryn Boys. 2021. Local food supply chain dynamics and resilience during COVID-19. Applied Economic Perspectives and Policy 43: 86-104

Thornton, Thomas F., and Nadia Manasfi. 2010. Adaptation-Genuine and spurious: demystifying adaptation processes in relation to climate change. Environment and Society: Advances in Research 1: $132-155$
Tilman, David, Peter B. Reich, Johannes Knops, David Wedin, Troy Mielke, and Clarence Lehman. 2001. Diversity and productivity in a long-term grassland experiment. Science 294: 843-845.

Toensmeier, Eric. 2016. The carbon farming solution: A global toolkit of perennial crops and regenerative agriculture practices for climate change mitigation and food security. Hartford, VT: Chelsea Green Publishing.

Travis, Joseph, Felicia C. Coleman, Peter J. Auster, Philippe M. Cury, James A. Estes, Jose Orensanz, Charles H. Peterson, Mary E. Power, Robert S. Steneck, and J. Timothy Wootton. 2013. Integrating the invisible fabric of nature into fisheries management. Proceedings of the National Academy of Sciences 111: 581-584.

Trivette, Shawn A. 2012. Close to home: the drive for local food. Journal of Agriculture, Food Systems, and Community Development. 3 (1): 161-180.

Vandermeer, John, Aniket Aga, Jake Allgeier, Catherine Badgley, Regina Baucom, Jennifer Blesh, Lilly F. Shapiro, et al. 2018. Feeding prometheus: an interdisciplinary approach for solving the global food crisis. Frontiers in Sustainable Food Systems 2: 39 .

Vermeulen, Sonja J., Bruce M. Campbell, and John S.I.. Ingram. 2012. Climate change and food systems. Annual Review of Environment and Resources 37: 195-222.

Weber, Keith T., and Shannon Horst. 2011. Desertification and livestock grazing: The roles of sedentarization, mobility and rest. Pastoralism: Research, Policy and Practice 1: 19.

White, Courtney. 2014. Grass, Soil, Hope: A Journey Through Carbon Country. Hartford, VT: Chelsea Green Publishing.

Witter, Allison, and Joshua Stoll. 2017. Participation and resistance: Alternative seafood marketing in a neoliberal era. Marine Policy 80: $130-140$

Publisher's Note Springer Nature remains neutral with regard to jurisdictional claims in published maps and institutional affiliations.

Philip A. Loring is an Associate Professor in the Department of Geography, Environment, and Geomatics at the University of Guelph, where he holds the Arrell Chair in Food, Policy, and Society. A human ecologist, his research interests include sustainable food systems, societal transitions, and social and environmental justice. 